\title{
Ainda o populismo: desta vez, o protagonismo negro
}

Yet Populism: this Time, the Black Protagonism

Elio Chaves Flores *

DOMINGUES, Petrônio. Estilo Avatar: Nestor Macedo e o populismo no meio afro-brasileiro. São Paulo: Editora Alameda, 2018. 265 p.

Eu quando estou com fome quero matar o Janio, quero enforcar o Adhemar e queimar o Juscelino. As dificuldades corta o afeto do povo pelos políticos (Carolina Maria de Jesus, 1960).

O historiador Petrônio Domingues (Universidade Federal de Sergipe) tornou-se documentalista de um campo de estudos que ajudou a formatar: o Pós-Abolição. Escolhido um determinado tema da República brasileira, sempre com recorte racial, não há acervo, fonte e documento que não acabe sendo visitado, folheado e interpretado pelo pesquisador, ávido por novas fontes e documentos nunca dantes arrolados. Nem todo historiador exercita a qualidade do documentalista, uma vez que não é incomum, na instituição historiadora, aquele vício soberbo que arrebata boa parte de nós, para a glória acadêmica e de currículos "serventes da erudição". Imerso nos arquivos, o professor Domingues entra e sai de lá para escrever, à moda thompsoniana, "contra o peso das ortodoxias predominantes" (Thompson, 1987, p. 12).

No seu último livro, que passo a resenhar, Petrônio Domingues não escapa de adensar o que parece ter sido o grande debate historiográfico da segunda metade do século XX, ajudando a fixar marcadores da teoria social do nosso tempo: as visadas do populismo e do trabalhismo, a classe e a raça, a dominação e as subalternidades no escopo da brasilidade mestiça; essa mitografia pensada e sugerida como forma e conteúdo da República.

\footnotetext{
* Universidade Federal da Paraíba (UFPB), João Pessoa, PB, Brasil. eliochavesflores@gmail.com $<$ https://orcid.org/0000-0002-8732-1557>
} 
Duas personalidades emergem da pesquisa historiográfica de Petrônio Domingues: o negro Nestor Macedo e a Ala Negra Progressista (ANP), entidade por ele fundada. O primeiro é uma individualidade dissonante na política brasileira. Já a segunda é registro da emergente coletividade negra da cidade de São Paulo, na profusão de políticos e de culturas políticas no contexto de intensa urbanização e proletarização do mundo do trabalho.

Começo pelo final. O último documento assinado por Nestor Macedo e analisado pelo historiador data de 18 de julho de 1978 e se denomina "Manifesto de alerta aos trabalhadores e ao povo em geral de São Paulo". Nele, hipoteca-se "integral apoio" ao partido da ditadura militar - ARENA - e às candidaturas de João Baptista Figueiredo, para a sucessão de Ernesto Geisel na presidência da República, e de Paulo Salim Maluf, para a sucessão de Paulo Egídio Martins no governo do Estado de São Paulo. Nestor Macedo pretendia-se governista, pela ordem e pelos "esteios populares dos trabalhadores e do povo em geral", conforme documento encontrado nos arquivos do DEOPS, AESP, e reproduzido em fac-símile no último "Caderno de Imagens" da obra (Domingues, 2018, p. 211). Tal documento testemunha uma espécie de fim de carreira desse homem negro que nunca fora visto pela historiografia, até que Petrônio fosse a esses arquivos virgens e segredados. Assim ele escreveu: "Possivelmente, depois dessa declaração pública de alinhamento e fidelidade ao regime militar, ele foi perdendo o fulgor, extenuando-se e deixando de participar cada vez mais do pulsante cenário político. Sua idade [72 anos] já não ajudava. Até que deu o último passo no caminho que julgava redentor e saiu da vida para, hoje, parte de suas venturas e desventuras entrar nos anais da história" (Domingues, 2018, p. 201). "Sair da vida" pode ser um ato menos prosaico para aquele afro-populista menos afortunado que, por "políticas de raça", não exerceu a clava da necropolítica.

Mas, o que significava a Ala Negra Progressista e quem foi, então, Nestor Macedo? Por que o historiador chacoalha a teoria social do fenômeno do populismo no Brasil? Como argumentar, pelo viés historiográfico, sobre "o populismo no meio afro-brasileiro" de meados do século XX?

$\mathrm{O}$ início de tudo está no testemunho, anterior à ida ao arquivo e à busca de comprovação. Depois, a conversa é com a memória arquivada, e disso a historiografia se compraz, como lembrou Paul Ricoeur: "o nascimento do arquivo, coligido, conservado, consultado” (Ricoeur, 2007, p. 155). Por isso, faz bem à resenha trazer os dois primeiros documentos apresentados por Petrônio Domingues: Os Estatutos da ANP, registrados no Cartório Oficial de Registro de Títulos e Documentos e Civil de Pessoa Jurídica de São Paulo, em 21 de 
dezembro de 1948; e os Extratos dos Estatutos da ANP, publicados no Diário Oficial do Estado de São Paulo, no dia 1 de janeiro de 1949. Essa seria a "memória arquivada" da reunião realizada no dia 8 de dezembro, no bairro do Cambuci, por um grupo de "indivíduos de cor" que teve como objetivo "fazer a propaganda da raça, e promover a sua união". Pretendiam os seus fundadores que a entidade deveria ser "órgão de propaganda cívica e educacional" e "sociedade de âmbito nacional". A ousadia era um programa que seria chamado de populista pelas elites intelectuais e econômicas: construir hospitais para amparar velhos, creches para as crianças, escolas para a "infância intelectual", ensinar trabalhos manuais e "tratar de assuntos políticos, estaduais e nacionais" (Domingues, 2018, p. 47). Petrônio Domingues considera a associação fundada de cunho nacionalista e constata essa perspectiva: "Percebe-se, assim, como a Ala Negra Progressista inscrevia em capítulos, artigos e parágrafos dos seus estatutos a preocupação com o negro na política” (Domingues, 2018, p. 48).

Bem, cada qual reivindica o que precisa e deseja. Mas, onde já se viu isso, negro na política? Logo vieram acusações do tipo: negro na política é populismo, negro na política é desatino, negro na política é corrupção.

Embora a "democracia racial" andasse de vento em popa como uma realização republicana, e seus ideólogos se vangloriassem que viviam numa sociedade mestiça - e, pasmem, sem racismo -, havia, na cena política, um ranço escravocrata e temeroso de qualquer ideia de "mobilização racial" por parte de lideranças e entidades negras.

A ANP turbinava a agenda política com discursos cívicos, reuniões dançantes, churrascos, sorteios, e não descuidava do combate "ao alcoolismo e ao analfabetismo dos homens de cor" - dois estigmas cinicamente colados à população negra pelas subjetividades da branquitude no pós-abolição. Trata-se da tese do interdisciplinar - e indisciplinado - Clóvis Moura: "o negro, de bom escravo a mau cidadão”? (Moura, 1977). Eis aí a pré-história do populismo. Você me entende?

Do âmbito das culturas populares da primeira metade do século XX - da imprensa, de entidades, territórios e gentes negras -, a pesquisa de Petrônio Domingues circunscreve Nestor Macedo, essa individuação que logo se autodeclara "o rei dos bailes populares" (Domingues, 2018, pp. 19, 83-104, 128,137, $140,148,149,229)$. Macedo imbrica-se, então, com candidatos, partidos políticos, comícios e passeatas, e passa a fazer "política como vocação" - é a minha hipótese de leitura. Essa expressão da sociologia weberiana ainda nos salvará da sempre retornada "maldição do populismo"?

Imaginem a campanha eleitoral nas eleições municipais de 1951, na cida- 
de de São Paulo: Getúlio Vargas e Adhemar de Barros, juntos e apoiando o candidato a vereador Paulo Vieira, advogado que, segundo Nestor Macedo, era "o grande candidato populista" que defenderia as bandeiras da Ala Negra Progressista e Trabalhista. A entidade havia mudado de nome para fixar a aliança política entre o PTB e o PSP. No material impresso da campanha, as fotos de Getúlio Vargas, Paulo Vieira e Adhemar de Barros aparecem nessa ordem. Abaixo da mensagem "Alerta aos Trabalhadores" consta a foto de Nestor Macedo e a síntese do programa da ANPT: "Creche, direito das favelas, velhice desamparada, assistência social, transporte para os bairros afastados, água, luz" (Domingues, p. 148). Nomear a vida é o barato da teoria, especialmente da vida política. A política escorria pelas tintas de panfletos, prospectos e cartazes.

Petrônio Domingues retira da documentação a interpretação que lhe é devida e dinamiza o significado de populismo sem deixar de, também, criticar o seu possível sucedâneo categorial, o trabalhismo. Antes das chispas da teoria social, o contexto exato de uma expressão tão mal afamada:

Em 1951, o termo populista não tinha uma conotação negativa - sinônimo de demagogia ou manipulação das massas -, sendo empregado para adjetivar as figuras carismáticas, que sabiam se comunicar com o povo (especialmente com o povo trabalhador, organizado ou não em sindicatos e associações voluntárias) e desfrutavam de alto índice de aceitação popular. É nesse sentido, aliás, que deve ser interpretado o título conferido a Nestor Macedo: o popular Rei dos Bailes. Tudo indica que esse título não era obra do acaso. Conjugado à parolagem habitual, ao dinamismo impetuoso e à facilidade de transitar entre os segmentos dos bairros periféricos, ele organizou mais de 15 bailes reunindo em média 300 pessoas - isto considerando tão somente a campanha eleitoral de 1951 (Domingues, 2018, p. 141, grifos do autor).

Um panfleto político é um discurso posicionado. É, como se diz no pretuguês da Lélia Gonzalez, "Cumé que a gente fica?" - e, em que medida a teoria ilumina as fontes com "discurso e mais discurso"? (Gonzalez, 1984, p. 223). Noutro panfleto, distribuído no mês de agosto de 1951, no bairro de Osasco, o historiador encontrou novamente a menção de que os candidatos coligados do PSP e do PTB, Paulo Vieira e Maxil Evangelista Barbosa, seriam "candidatos únicos populistas de Getúlio e Adhemar” (Domingues, 2018, p. 142). Então, dê-lhe baile, festa e churrasco para os convidados e simpatizantes. Pedem-se votos, ouvem-se discursos, carregam-se nas promessas, nos ditos e nos feitos. 
Petrônio demonstra que a participação política da população negra se conota ao regime democrático que vai sendo revirado por estigmas e processos raciológicos de negação da cidadania, até chegarmos a uma data iceberg: 1964, que não chega a retirar Nestor Macedo para fora da política. Trata-se disso:

Chama a atenção saber que os candidatos apoiados pelos A. N. P. - Paulo Vieira e Maxil Evangelista Barbosa - eram definidos como os únicos populistas. Mais uma vez, o termo populista não se referia a um político que se valia da empulhação, da demagogia ou má fé. Revestindo-se de outro significado, referia-se ao que na linguagem corrente se chama de político popular, alguém que representa, efetivamente, as aspirações e expectativas políticas do povo. Em vez de depreciativa, a adjetivação populista era evocada como atributo positivo, denotando ao termo, portanto, o sentido de elogio, enaltecimento. Isto corrobora a assertiva segundo a qual o termo populismo nasceu como uma virtude, tendo sido ressignificado no imaginário popular depois do golpe de 1964, quando passou de virtude para pecha, da qual todos os políticos queriam se livrar (Domingues, 2018, pp. 142-43, grifos do autor).

Petrônio Domingues traz à tona o debate sobre populismo e trabalhismo na história e nas culturas políticas no Brasil, especialmente depois do fim do Estado Novo. Assim foi feito a partir de obra polêmica organizada pelo historiador Jorge Ferreira, O populismo e sua história: debate e crítica (2001), a qual eu tive a possibilidade de resenhar para "defender" o trabalhismo como categoria sociológica e historiográfica e, assim, também me opor à ideia de "colapso do populismo" - as "intuições sociológicas” de Octávio Ianni e Francisco Weffort simplesmente não viram o colapso da República e da própria democracia. A sociologia interessada acusou as vítimas pelos atos das direitas empoderadas no pós-1964. Fiquei com a hipótese do historiador Daniel Aarão Reis Filho, de que "do trabalhismo se fez o populismo" (Reis Filho, 2001, p. 347).

A resenha foi publicada na revista Politeia (2002, pp. 207-219) e, naquela conjuntura, apontei três correntes de intérpretes do populismo: a) a primeira, de olhar sociológico, ainda não havia abandonado os postulados teóricos do populismo, "a maldição do povo na política"; b) a segunda considera o populismo, desde a década de 1980, como não mais adequado para se entender o Estado e as culturas políticas e, menos ainda, a classe trabalhadora; c) a terceira rejeita o populismo, por se constituir em categoria de acusação e de desqualificação do outro, ao situar as vozes udenistas e conservadoras do espectro político. Vinte anos depois, nem a categoria trabalhismo contempla a ampli- 
tude do debate da "história social do trabalho", que, ao final do século XX, se arregimentava "na luta por direitos" (Fortes et al, 1999). Jovens historiadores thompsonianos ganharam a dianteira, depois da icônica definição de "o nome e a coisa”, e já temos variações de inglesias e outras peculiaridades (Negro, 2004; Fortes et al., 2013). Então: populismo, trabalhismo? Vem, Thompson, vem em nosso socorro: "em vez de golpear a história para salvar as categorias, devemos instigá-las com novas análises” (Thompson, 2001, p. 276).

Muitos ficaram para trás. Desde a década de 1980, eu saudava a admirável tese defendida na área da ciência política, publicada com o título de $A$ invenção do trabalhismo (Gomes, 1994 [1988]), de autoria de Angela de Castro Gomes. A crítica ao populismo como um "felino de sete vidas" e a convicção de que os trabalhadores também seriam atores e autores de pactos políticos soaram como significativas inovações da teoria social. Esse olhar carioca se desvaneceu, a meu ver, muito rapidamente, no decorrer do século XXI. Até mesmo o cáustico - e não menos brilhante - Ernesto Laclau escreveu uma obra definitiva, $A$ razão populista (2013 [2005]).

Petrônio Domingues flerta mais com a leitura thompsoniana da história e considera o conceito de trabalhismo "um louvável tour de force teórico-metodológico", mas que não se torna operativo para se compreender o protagonismo afro-brasileiro na República - especialmente no que concerne à São Paulo adhemarista e janista -, bem como os demais políticos "populistas" (aqui considerados na definição mesma do "Rei das Festas Populares"). Domingues conecta a imagem inebriante da trajetória de Nestor Macedo e afirma ser limitadora a visão do mundo do trabalho pela ótica das relações de fábrica e da mediação sindical. Isso não é tudo: "O fazer-se da classe trabalhadora ocorria dentro e fora das fábricas, por meio das tradições, das crenças, dos ritos, dos símbolos, dos valores, das atividades recreativas, enfim, por meio dos espaços de sociabilidade, cultura e lazer (Domingues, 2018, pp. 225-226). Nestor Macedo se autodeclarava adhemarista, progressista e trabalhista, e convocava os afro-brasileiros para convescotes e bailes populares, como esse na Vila Moraes, no dia $1 .^{\circ}$ de maio de 1952, em que agradecia os representantes dos Estados de São Paulo, Minas Gerais e Bahia pelo patrocínio do evento. No segundo parágrafo do panfleto emerge a "razão populista", se é que a teoria ilumina o fato: "Nesse dia e com a presença de representantes patriotas desses três magníficos Estados da Federação, será inaugurado o retrato do insigne Presidente da República, impoluto chefe da nação brasileira [Getúlio Vargas] e protetor de todos os trabalhadores de nossa extremecida pátria; do digno Governador de São Paulo, Dr. Lucas Nogueira Garcez, figura majestosa de administrador e do Dr. 
Ademar de Barros, ilustre Chefe populista e esperança do povo brasileiro" (Domingues, 2018, p. 173, grifos meus).

A trajetória de Nestor Macedo lembra o percurso de Carolina Maria de Jesus. Ambos são mineiros e se deslocaram, no pós-abolição, para o interior de São Paulo, chegando à capital para os avatares de uma vida afro-brasileira. Macedo nasceu na cidade de São José Além Paraíba - desde 1923, apenas Além Paraíba -, na divisa com o Rio de Janeiro, mais próxima da capital fluminense do que da capital de Minas Gerais, no dia 19 de fevereiro de 1907. É filho de Joaquim Macedo e Leocádia Maria da Conceição - nomes de pessoas invisibilizadas, pois o autor desconhece quaisquer outros dados do pai e da genitora. Sabe-se que Nestor Macedo foi criado na cidade de Mogi das Cruzes, no Estado de São Paulo, lugar aonde chegou aos 12 anos, portanto, por volta de 1919, ali exercendo a atividade de entregador de pão de porta em porta. No ano de 1933, então com 26 anos, já se encontrava na capital, onde trabalhou como varredor de rua, na Seção de Limpeza Pública da Prefeitura de São Paulo. Como Carolina Maria de Jesus faria depois, ele juntou papel velho, osso, lata, e vendia tudo para o depósito de um italiano, situado à Rua Augusto de Queiroz. Tornou-se poupador para poder comprar um carrinho de mão e se registrar como ambulante, e vendia "cebolas e batatas por toda a cidade" (Domingues, 2018, p. 52). Aos 35 anos, em 1942, foi preso pela primeira vez e fichado pelo Prontuário 44.317-DEOPS/AESP, pelo "crime" genérico à economia popular. Na ocasião, declarou ser casado e comerciário, e informou ter residido em vários endereços, com notável mobilidade sazonal e "deslocamentos que salpicaram" uma vida itinerante.

No ano de 1949, já como principal expressão da Ala Negra Progressista, lançaria um manifesto "ao glorioso povo paulista", no qual se apresentava como "representante da raça de cor humilde", afirmando que percorria "todas as favelas de São Paulo" e conhecia "o sofrimento da nossa gente" (Domingues, 2018 , p. 53). Declarava que, como "pertencente à raça negra", devia "lutar como o fez José do Patrocínio, Luiz Gama, Francisco Lucrécio, Joaquim Nabuco e a redentora Princesa Isabel". Nestor Macedo pinçava personalidades atraentes ao discurso racial, ao mesmo tempo em que declarava apoio ao Partido Progressista e ao governador Adhemar de Barros. Parece que Macedo teve presença política intensa na década de 1950, especialmente no contexto das eleições municipais e estaduais. Não raras vezes, viu-se envolvido em perrengues, acusações e denúncias às autoridades públicas, com os desafetos políticos de correntes de esquerda, supostamente comunistas e socialistas. Um episódio envolvendo Nestor Macedo e Luiz Lobato, atuante em várias entida- 
des de esquerda, organizações negras e, também, militante do PSB, é narrado em pormenores na obra, para exemplificar que "os movimentos sociais não constituíam um bloco monolítico; antes, se caracterizavam pela pluralidade morfológica e ideológica" (Domingues, 2018, p. 102). O PSB de Luiz Lobato e o PSP de Nestor Macedo estavam tão distantes no espectro ideológico quanto o B está longe do $\mathrm{P}$ na ordem alfabética.

Depois de apresentar a trajetória de Nestor Macedo, o autor de Estilo Avatar lança três questões que serão respondidas no decorrer dos capítulos: "Nestor Macedo era um líder afro-brasileiro loquaz, dotado de uma retórica político-partidária. Mas por que ele e a Ala Negra Progressista apoiavam o populista Adhemar de Barros? Tendo em vista o marcador racial, não se tratava de um gesto falacioso, de alienação ou mesmo de contrassenso confiar num político demagogo, paternalista e manipulador das massas? Ou o apoio a Adhemar de Barros deve ser visto como uma atitude consciente e legítima de um pugilo de negros que fazia da política a arte do possível, barganhando identidades, alianças e negociações diversas?” (Domingues, 2018, p. 54). Ao partir da individuação para as subjetividades da identidade racial, Petrônio Domingues quer saber "como se operou o processo e até que ponto o populismo conseguiu - ou tentou - penetrar no meio afro-paulista" (Domingues, 2018, p. 54).

A expressão o "Rei dos bailes populares" fundamenta um capítulo da obra e apresenta a vida de um "Nestor Macedo, equilibrista": entre a organização de bailes e festas populares, as pelejas pela ANP e outras agremiações negras - como a Sociedade Recreativa e Beneficente da Abolição -, e aderente às políticas e práticas adhemaristas. Pelejava mesmo. O historiador mostra mancheias as ocasiões em que ele esteve nas delegacias e foi frequentador assíduo dos prontuários do DEOPS/SP. Parecia até uma tática de presença política, querer-se "um líder negro ilibado, bem sucedido e detentor de capital político" (Domingues, 2018, p. 92). Com efeito, havia ambiguidades e escolhas: "Não temos dúvidas é de que Macedo costumava frequentar delegacias e incorrer em práticas consideradas escusas ou mesmo ilícitas. Na fase de suas atividades à frente da Ala Negra Progressista, esse quadro não mudou. Foram vários os episódios, relacionados a essa agremiação, que viraram caso de polícia política e de ordem social e foram parar no Deops” (Domingues, 2018, p. 92).

O capítulo final, "O populismo no meio afro-brasileiro", usa a expressão "estribado por Edward P. Thompson" para fundamentar a noção de que, num "viés específico de populismo", é possível perceberem-se antagonismos, campos de força e liames de dependências políticas e eleitorais. A tese forte é a de 
que Nestor Macedo adotou o adhemarismo por convicção, "como uma escolha, uma atitude consciente"; tentou tirar vantagens, correu riscos, buscou direitos e ajuda material para a "população de cor" e, portanto, "não tinha nada de alienado ou subserviente" (Domingues, 2018, p. 175). Decerto que houve uma espécie de "mística populista" e, em São Paulo, o doutor Adhemar de Barros não deixou de cortejar e ser cortejado pelo meio afro-brasileiro. A tese fraca é a de que "Adhemar não era qualquer populista", uma vez que "foi representado e visto como uma das primeiras autoridades públicas a conferir ao negro a posição menos de figurante e mais de ator, que - assim como qualquer componente do jogo do poder - não devia ser negligenciado no xadrez da política" (Domingues, 2018, pp. 174-176, 227). Defino a "tese fraca" porque, em mais de setenta anos de historiografia, a imagem de Adhemar de Barros na política brasileira não foi, ainda, deslocada daquele espectro político do rouba, mas faz; me engana que eu gosto.

As pesquisas de Angela de Castro Gomes (1994, 2001, 2002) e dos demais historiadores "da invenção do trabalhismo" e críticos do populismo (Ferreira, 2001; Reis Filho, 2001; Flores, 2002) tiveram o mérito de sacudir o "lixo do estigma” das trajetórias de Getúlio Vargas, João Goulart, Miguel Arraes e Leonel Brizola (entre outros), assim como desconstruíram a "lógica explicativa" dos estudos sindicais no Brasil, a noção de que, não sendo um sindicato radicalmente posicionado, somente poderia ser, então, pelego. Dito de outra forma, o peleguismo é para o sindicato e o trabalhador o equivalente do que o populismo é para o político e o partido político, a depender dos naipes ideológicos.

Quanto ao populismo adhemarista e às suas relações com as entidades e pessoas negras, o elemento novo quem traz é o próprio Petrônio Domingues: a possibilidade de um Adhemar "negritudinista", tocado pelo "negrismo" de Nestor Macedo, "esse avatar, que não perdia a oportunidade de transmutar" (Domingues, 2018, p. 230). Afirma-se isso para que se pense na mobilização racial e - por que não? - na formação e na construção da consciência racial. Da leitura dessa obra do historiador Petrônio Domingues, é alentador depreender que Nestor Macedo e a Ala Negra Progressista - ANP, com suas escolhas e ambiguidades, estão inscritos "nas culturas políticas do Atlântico Negro" (Domingues, 2018, p. 231).

Para concluir, não é de menos importância lembrar que o mundo do trabalho e a cultura política no Brasil foram (e ainda são) atravessados pelo racismo estrutural. Os trabalhadores negros e as mulheres negras, ainda que participassem de sindicatos e de partidos políticos, foram historicamente in- 
visibilizados como pessoas de dignidade e portadoras de direitos. Os recentes casos de violência racial, cada vez mais frequentes no cotidiano do trabalho e na vida cotidiana, expressam as desigualdades materiais de uma sociedade construída a ferro e a fogo pelos marcadores raciais. Por isso, a leitura e a apreciação da obra historiográfica de Petrônio Domingues permite a visibilidade do protagonismo negro.

\section{REFERENNCIAS}

DOMINGUES, Petrônio. Estilo Avatar: Nestor Macedo e o populismo no meio afro-brasileiro. São Paulo: Editora Alameda, 2018. 265 pp.

FERREIRA, Jorge. (Org.). O populismo e sua história: debate e crítica. Rio de Janeiro: Civilização Brasileira, 2001. 380 pp.

FLORES, Elio Chaves. [Resenha de] FERREIRA, Jorge. (Org.). O populismo e sua história: debate e crítica. Rio de Janeiro: Civilização Brasileira, 2001. POLITEIA: Hist. e Soc. v. 2, n. 1, pp. 207-219, 2002.

FORTES, Alexandre et al (Orgs.). Na Luta por Direitos. Estudos recentes em história social do trabalho. Campinas: Editora Unicamp, 1999.

FORTES, Alexandre et al (Orgs.). Cruzando Fronteiras: novos olhares sobre a história do trabalho. São Paulo: Editora Perseu Abramo, 2013. 304 pp.

GOMES, Angela de Castro. A Invenção do Trabalhismo. 2. ${ }^{\text {a }}$ ed. Rio de Janeiro: Relume-Dumará, 1994 [1988].

GOMES, Angela de Castro. O populismo e as ciências sociais no Brasil: notas sobre a trajetória de um conceito. In: FERREIRA, Jorge. (Org.). O populismo e sua história: debate e crítica. Rio de Janeiro: Civilização Brasileira, 2001. pp. 17-57.

GOMES, Angela de Castro. Reflexões em torno de populismo e trabalhismo. Varia Historia, n. 28, pp. 55-68, 2002.

GONZALEZ, Lélia. Racismo e sexismo na cultura brasileira. Revista Ciências Sociais Hoje, ANPOCS, pp. 223-244, 1984.

JESUS, Carolina Maria de. 16 de maio de 1958. In: Quarto de Despejo: diário de uma favelada. São Paulo: Editora e Livraria Francisco Alves, 1960.

LACLAU, Ernesto. A Razão Populista. São Paulo: Três Estrelas, 2013 [2005].

MOURA, Clóvis. O Negro: de bom escravo a mau cidadão? Rio de Janeiro: Editora Conquista, 1977.

NEGRO, Antonio Luigi. Apresentação. Cadernos AEL: populismo e trabalhismo. Campinas: IFCH-AEL, v. 11, n. 20-21, pp. 7-8, 2004.

REIS FILHO, Daniel Aarão. O colapso do populismo ou a propósito de uma herança maldita. In: FERREIRA, Jorge. (Org.). O populismo e sua história: debate e crítica. Rio de Janeiro: Civilização Brasileira, 2001. pp. 319-377. 
RICOEUR, Paul. A memória, a história, o esquecimento. Campinas: Editora Unicamp, 2007.

THOMPSON, Edward Palmer. A Formação da Classe Operária Inglesa. Vol. I: A árvore da liberdade. Rio de Janeiro: Paz e Terra, 1987.

THOMPSON, Edward Palmer. As peculiaridades dos ingleses e outros artigos. NEGRO, Antonio Luigi; SILVA, Sergio (Orgs.). Campinas: Editora Unicamp, 2001. 